\title{
ANALISIS PENGENDALIAN AIR PERMUKAAN DI BAWAH FLY OVER DENGAN SISTIM DRAINASE TERPADU PADA KASUS RUAS JALAN MEKAR MUKTI - CIBARUSAH DENGAN PENDEKATAN MODEL HIDROLIK EKSPERIMEN LABORATORIUM
}

\author{
Bakhtiar AB, Dede Muhammad Yahya \\ Program Studi Teknik Sipil Universitas Sangga Buana
}

\begin{abstract}
ABSTRAK
Drainase mempunyai arti mengalirkan, menguras, membuang, atau mengalihkan air. Secara umum, drainase didefinisikan sebagai serangkaian bangunan air yang berfungsi untuk mengurangi dan/atau membuang kelebihan air dari suatu kawasan atau lahan, sehingga lahan dapat difungsikan secara optimal. Drainase juga diartikan sebagai usaha untuk mengontrol kualitas air tanah dalam kaitannya dengan sanitasi. Dalam perencanaan saluran drainase harus memperhatikan tata guna lahan daerah tangkapan air saluran drainase yang bertujuan menjaga ruas jalan tetap kering walaupun terjadi kelebihan air, sehingga air permukaan tetap terkontrol dan tidak mengganggu pengguna jalan.Fly over Cikarang adalah jembatan yang berada di ruas jalan provinsi yang menghubungkan desa Mekar Mukti di Kecamatan Cikarang Utara dan desa Cibarusah Kecamatan Cibarusah Kabupaten Bekasi, berada pada koordinat $107,14373^{\circ} \mathrm{BT} 6,30992^{\circ} \mathrm{LS}-107,14735^{\circ} \mathrm{BT} 6,31386^{\circ} \mathrm{LS}$ sepanjang $250,00 \mathrm{~m}$. Pada musim penghujan, dibawah fly over sering terdapat genangan akibat air hujan yang tidak mengalir sehingga mengakibatkan kerusakan baik pada permukaan jalan maupun trotoar. Metode yang dilakukan dalam penelitian ini adalah eksperimen laboratorium yang dilakukan dengan mengadakan pemodelan terhadap objek penelitian. Eksperimen laboratorium menurut Moh Nasir (1988), adalah observasi dibawah kondisi buatan (artifical condition), yang kondisinya dapat diatur dan dibuat oleh peneliti.
\end{abstract}

Kata Kunci: Air Permukaan, Drainase

\section{PENDAHULUAN}

\section{Latar Belakang}

Drainase kota adalah jaringan pembuangan air yang berfungsi mengeringkan bagianbagian wilayah administrasi kota dan daerah urban dari genangan air, baik dari hujan lokal maupun luapan sungai melintas di dalam kota (SK menteri PU No. 233 tahun 1987).

Drainase mempunyai arti mengalirkan, menguras, membuang, atau mengalihkan air. Secara umum, drainase didefinisikan sebagai serangkaian bangunan air yang berfungsi untuk mengurangi dan/atau membuang kelebihan air dari suatu kawasan atau lahan, sehingga lahan dapat difungsikan secara optimal. Drainase juga diartikan sebagai usaha untuk mengontrol kualitas air tanah dalam kaitannya dengan sanitasi (Dr. Ir. Suripin, M.Eng.2004)

Fly over Cikarang adalah jembatan yang berada di ruas jalan provinsi yang menghubungkan desa Mekar Mukti di Kecamatan Cikarang Utara dan desa Cibarusah Kecamatan Cibarusah 
Kabupaten Bekasi, berada pada koordinat $107,14373^{\circ}$ BT $6,30992^{\circ} \mathrm{LS}-107,14735^{\circ}$ BT $6,31386^{\circ}$ LS sepanjang $250,00 \mathrm{~m}$. Secara administratif, Fly Over Cikarang berada di Desa Pasir Sari Kecamatan Cikarang Selatan Kabupaten Bekasi. Pada musim penghujan, dibawah fly over sering terdapat genangan akibat air hujan yang tidak mengalir sehingga mengakibatkan kerusakan baik pada permukaan jalan maupun trotoar.

\section{Rumusan Masalah}

Perumusan masalah yang akan dilakukan dalam analisa ini untuk mencari solusi dalam mengatasi masalah kerusakan infrastruktur jalan yang di akibatkan oleh tingginya intensitas hujan di kawasan genangan air, dengan Menganalisis serta mengaplikasikan kedalam data-data yang berkaitan pada kajian genangan banjir. Untuk itu penulis akan menguji tentang masalah tersebut, dilakukan dengan pendekatan eksperimen uji model hidrolik secara handal dan sebagai aplikasi nya adalah Kecamatan Cikarang Utara Kabupaten Bekasi.

\section{Batasan Masalah}

Pembatasan masalah yang akan di analisa pada kerusakan infrastruktur jalan dan trotoar yang diakibatkan akibat tingginya curah hujan dan pengaruh sedimentasi yang terjadi pada aliran drainase, dimana aliran menjadi tersumbat hingga mengakibatkan banjir atau membuat genangan berdasarkan data eksperimen di laboraturium.

\section{Ruang Lingkup Penelitian}

Penelitian dilakukan di Laboratorium Teknik sipil USB (Universitas Sangga Buana -YPKP), dengan deskripsi sebagai berikut:

1. Mengidentifikasi data - data primer dari hasil kajian lapangan.

2. Mengkaji data - data sekunder.

3. Mengumpulkan data hasil penelitian yang berhubungan dengan debit hujan yang mempengaruhi kerusakan infrastruktur jalan dan trotoar.

\section{MAKSUD DAN TUJUAN}

\section{Maksud Penelitian}

Maksud dari penelitian ini adalah untuk memahami pentingnya perhitungan pada saat melakukan perencanaan Infrastruktur jalan dan trotoar, khususnya untuk menganalisa perbaikan jalan dan trotoar ketika terjadi genangan air dengan pendekatan kinerja intensitas hujan di Kecamatan Cikarang Utara Kabupaten Bekasi.

\section{Tujuan Penelitian}

Tujuan dari kegiatan penelitian ini adalah untuk :

1. Mencegah terjadinya kerusakan infrastruktur jalan dan trotoar yang merugikan, sehingga tidak merusak dan menurunkan kemampuan jalan; 
2. Memperbaiki kerusakan infrastruktur jalan dan trotoar untuk mengembalikan fungsi jalan dan trotoar sebagai mana mestinya;

3. Sebaga dasar untuk melakukan perencanaan atau pelaksanaan pekerjaan infrastruktur jalan;

\section{Manfaat Penelitian}

1. Ditinjau dalam bidang akademis

Sebagai aplikasi dari ilmu yang diperoleh dari bangku perkuliahan dengan cara mempraktikkannya langsung di lapangan. Kemudian dari hasil Tugas Akhir ini,

2. Ditinjau dalam bidang praktis Manfaat dari studi ini adalah mampu memberikan informasi terkait dengan kondisi yang ada untuk dijadikan dasar dalam memberikan usulan perbaikan kerusakan jalan dan trotoar di kawasan Cikarang Utara. Lebih jauh lagi menjadi umpan balik/masukan kepada pemerintah daerah dan seluruh pemerhati dalam menangani infrastrutur jalan dan trotoar yang selanjutnya mampu:

a. Menjadi dasar pembuatan manajemen perkotaan yang berwawasan lingkungan dalam ruang dan waktu.

b. Mempertahankan bangunan jalan dan terotoar sebagai salah satu sarana transportasi darat bagi masyarakat di wilayah.

c. Digunakan sebagai kerangka dasar pemikiran dalam hal pemilihan system infrastruktur kota yang berwawasan lingkungan dalam rangka upaya meningkatkan sarana transportasi.

\section{KAJIAN PUSTAKA}

\section{Pengertian Drainase}

Drainase adalah salah satu unsur dari prasarana umum yang dibutuhkan masyarakat dalam rangka menuju lingkungan yang aman, nyaman, bersih dan sehat.

\section{Sejarah Perkembangan Drainase}

Ilmu drainase perkotaan bermula tumbuh dari kemampuan manusia mengenali lembah-lembah sungai yang mampu mendukung kebutuhan hidupnya.

\section{Sistem Jaringan Drainase}

Sistem jaringan drainase perkotaan umumnya dibagi atas 2 bagian, yaitu:

a) Sistem Drainase Mayor

b) Sistem Drainase Mikro

Jenis-Jenis Drainase 
a) Menurut

\section{terbentuknya}

Natural Drainase

Artificial Drainase

b) Menurut letak saluran

Surface Drainage

Sub Surface Drainage

c) Menurut konstruksi

Saluran Terbuka

Saluran Tertutup

d) Menurut fungsi

Single Purpose

Multy Purpose

\section{Pola Jaringan Drainase}

Dalam perencanaan sistem drainase suatu kawasan harus memperhatikan pola jaringan drainasenya. Pola jaringan drainase pada suatu kawasan atau wilayah tergantung dari topografi daerah dan tata guna lahan kawasan tersebut.

Adapun tipe atau jenis pola jaringan drainase sebagai berikut.

a. Jaringan Drainase Siku
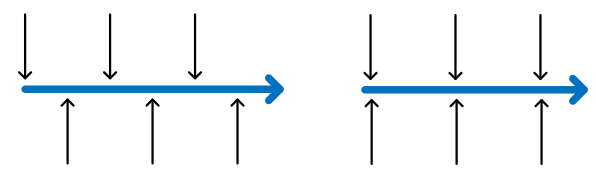

$\longrightarrow$ Saluran Utama

sejarah b. Jaringan Drainase Paralel

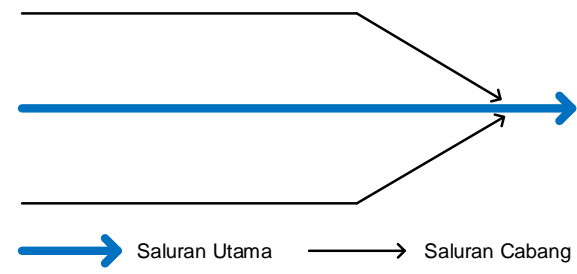

c. Jaringan Drainase Grid Iron

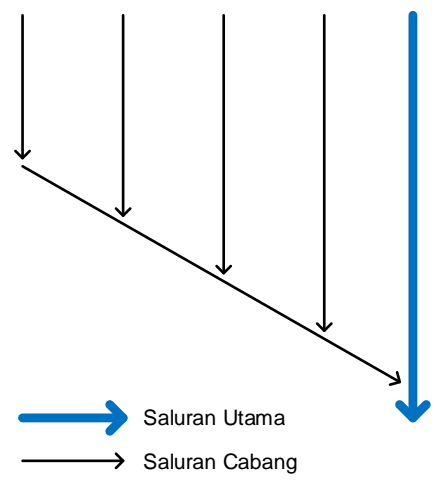

d. Jaringan Drainase Alamiah

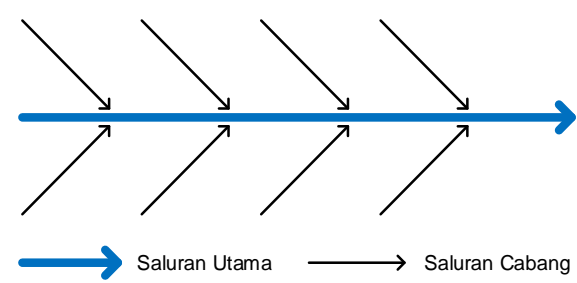

e. Jaringan Drainase Radial

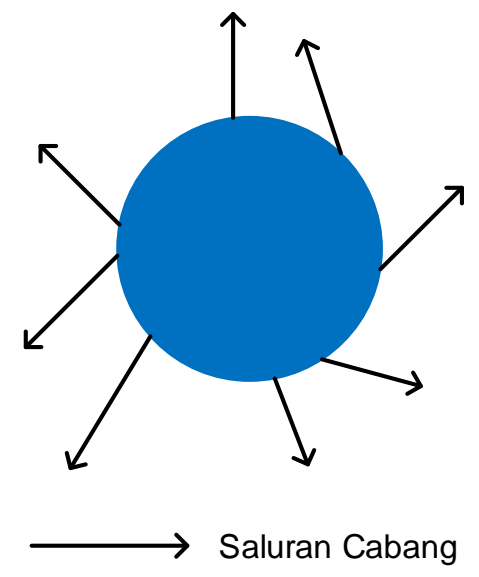

f. Jaringan Drainase Jaring-Jaring 


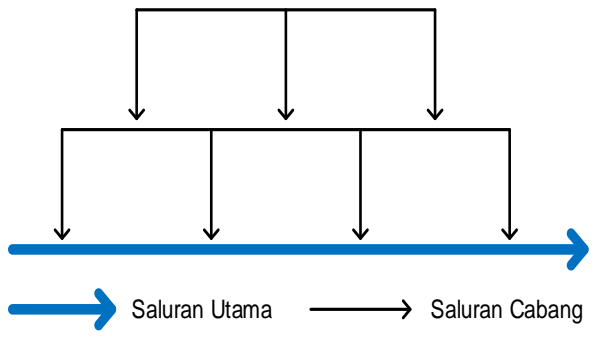

\section{Dimensi saluran}

a. Persegi Panjang

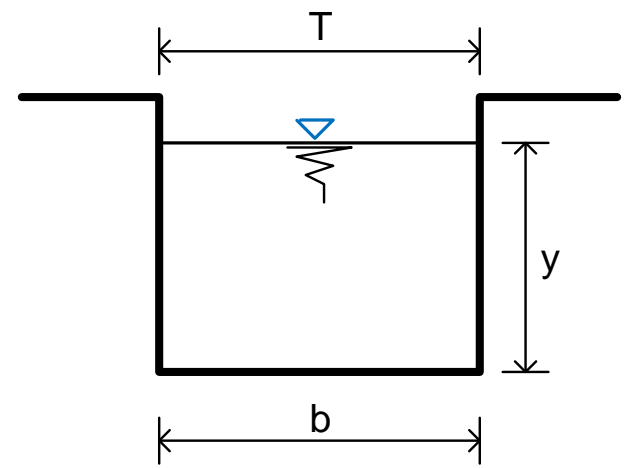

$\begin{array}{ll}\text { Luas }(\mathrm{A}) & =b \cdot y \\ \text { Keliling basah (P) } & =b+2 y \\ \text { Jari-jari Hidrolik (R) } & =\frac{b \cdot y}{b+2 y} \\ \text { Lebar Puncak (T) } & =b \\ \text { Kedalaman Hidrolik (D) } & =y \\ \text { Faktor Penampang (Z) } & =(b \cdot y)^{1,5}\end{array}$

b. Trapesium

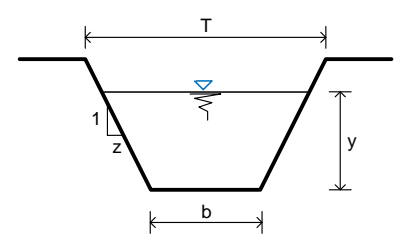

$$
\begin{array}{ll}
\text { Luas (A) } & =(b+z y) y \\
\text { Keliling Basah (P) } & =b+2 y \sqrt{1+z^{2}} \\
\text { Jari-jari Hidrolik } & =\frac{(b+z y) y}{b+2 y \sqrt{1+z^{2}}} \\
\text { Lebar Puncak (T) } & =b+2 z y \\
\text { Faktor Penampang } & =\frac{(b+2 z y) x y}{b+2 z y}
\end{array}
$$

Teori Analisis Hidrolika Saluran
Persamaan aliran satu dimensi ini menunjukkan kondisi aliran yang dinyatakan oleh dua variabel tak bebas $\boldsymbol{h}$ (tinggi air) dan $\boldsymbol{Q}$ (debit) untuk setiap titik di saluran. Variabel tak bebas ini menunjukkan kondisi aliran sepanjang saluran untuk setiap waktu $\boldsymbol{t}$.

Dasar persamaan kontinuitas unsteady flow pada saluran terbuka diturunkan sebagai persamaan berikut (Raju, 1986:9):

$$
\frac{d Q}{d x}=\frac{d A}{d t}=0
$$

\section{Dengan:}

$Q=$ debit $(\mathrm{m} 3 / \mathrm{dt})$

$\mathrm{X}=$ panjang pias $(\mathrm{m})$

$A=$ luas penampang $(\mathrm{m} 2)$

$\mathrm{t}=$ waktu (detik)

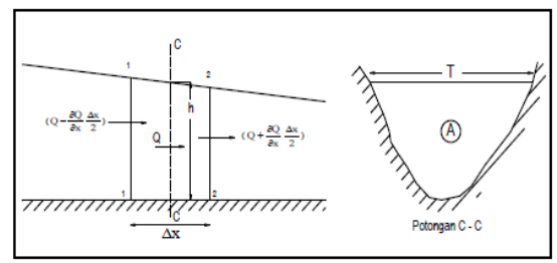

Kontinuitas Aliran Tak Tetap Sumber: Raju, 1986:9 


\section{Erosi Aliran Permukaan}

Erosi aliran permukaan akan terjadi hanya jika intensitas/lamanya hujan melebihi kapasitas infiltrasi/ kapasitas simpan air.

$$
R e=\frac{\rho \cdot V \cdot D}{\mu} \quad \operatorname{dan} F=\frac{V}{\sqrt{g \cdot D}}
$$

Karakteristik hidrolik aliran permukaan dapat diidentifikasi dengan bilangan Reymold (Re) dan bilangan Freude (F) pada persamaan :

Dimana:

$\rho \quad=$ massa air $\left(\mathrm{kg} / \mathrm{m}^{3}\right)$

$V=$ kecepatan aliran $(\mathrm{m} / \mathrm{det})$

$D \quad=$ jari-jari hidrolik aliran permukaan atau sama dengan kedalaman aliran permukaan

$=$ kekentalan kinematik air $(\mathrm{kg} / \mathrm{m} / \mathrm{det})$

$g \quad=$ percepatan gravitasi bumi $(\mathrm{m} /$ det $)$

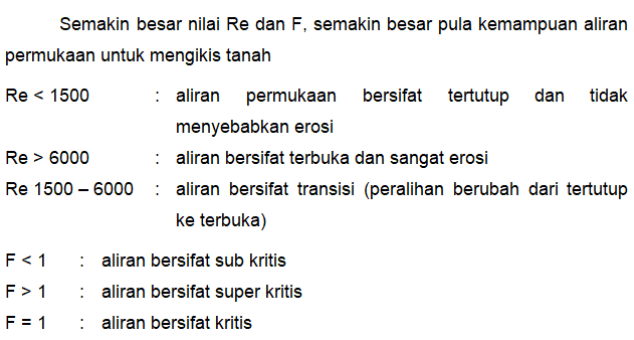

\section{METODOLOGI PENELITIAN}

\section{Prinsip Penelitian}

Metode penelitian merupakan suatu cara ilmiah yang dilakukan dengan tujuan tertentu yaitu mencari penjelasan dan jawaban dari suatu permasalahan, memberikan penjelasan dan jawaban dari suatu permasalahan serta memberikan alternatif kemungkinan yang dapat digunakan untuk pemecahan masalah. Penjelasan dan jawaban itu dapat bersifat abstrak atau umum sebagaimana halnya dalam penelitian dasar dan dapat pula sangat konkret dan spesifik seperti yang biasa ditemui dalam penelitian terapan.

\section{Jenis Penelitian}

Penelitian yang dilakukan dalam penelitian ini adalah eksperimen laboratorium yang dilakukan dengan mengadakan pemodelan terhadap objek penelitian. Eksperimen laboratorium menurut Moh Nasir (1988), adalah observasi dibawah kondisi buatan (artifical condition), yang kondisinya dapat diatur dan dibuat oleh peneliti.

\section{Lokasi Penelitian}

Pelaksanaan penelitian ini dilakukan di laboratorium uji model hidrolik (laboratorium hidrolik) Universitas Sangga Buana (YPKP) Bandung. Adapun waktu penelitian dilakukan dalam kurun waktu 4 (empat) hari. Lokasi penelitian sebenarnya berada di Fly over Cikarang yang berada di ruas jalan provinsi enghubungkan desa Mekar Mukti di Kecamatan Cikarang Utara dan desa Cibarusah Kecamatan Cibarusah Kabupaten Bekasi, berada pada koordinat $107,14373^{\circ}$ BT $6,30992^{\circ} \mathrm{LS}$ $107,14735^{\circ} \mathrm{BT} 6,31386^{\circ}$ LS sepanjang 250,00 m. Secara administratif, Fly Over Cikarang berada di Desa Pasir Sari Kecamatan Cikarang Selatan Kabupaten Bekasi. 


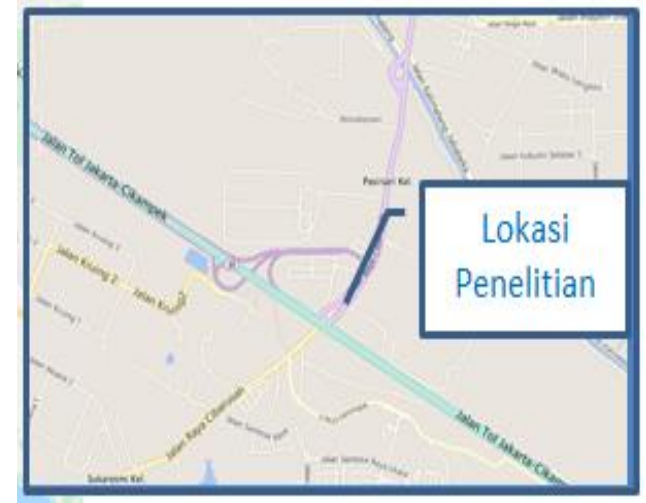

Peta Wilayah Fly Over Cikarang dan sekitarnya

Pada musim penghujan, dibawah fly over sering terdapat genangan akibat air hujan yang tidak mengalir sehingga mengakibatkan kerusakan baik pada permukaan jalan maupun trotoar.

\section{Bagan Alir Penelitian}

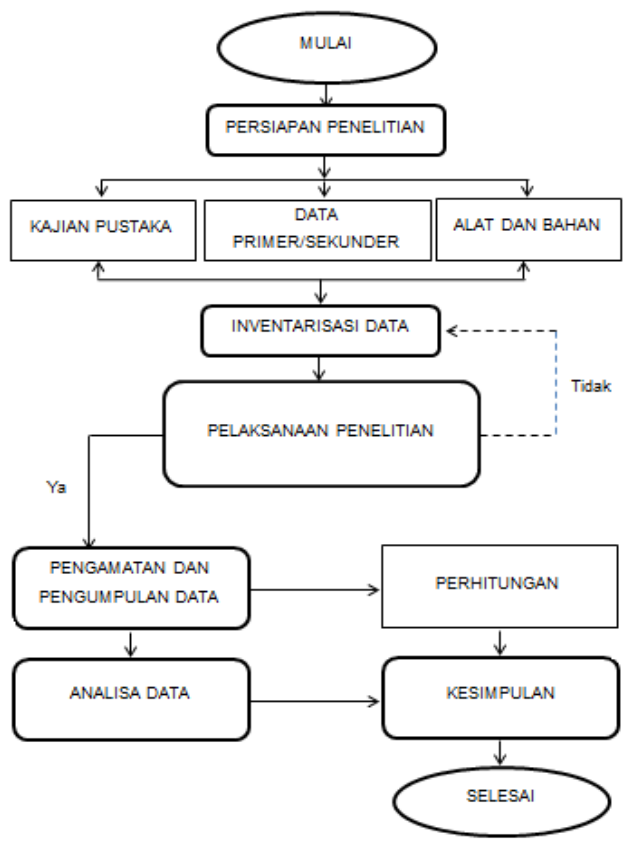

Gambar3. Bagan Alir Penelitian

\section{KAJIAN PUSTAKA}

Langkah awal yang harus diakukan adalah mempelajari literatur maupun jurnal yang berhubungan dengan bahasan pengkajian, sehingga dapat mengetahui apa sajah parameter yang dibutuhkan untuk menyusun laporan sesuai dengan topik atau bahasan yang dikaji.

\section{Penggunaan Alat dan Bahan}

Penelitian yang dilakukan membutuhkan beberapa alat dan bahan yang mendukung jalannya penelitian di laboratorium. Alat alat dan bahan tersebut sebagian besar sudah disediakan di laboratorium hidrolika saluran terbuka di Laboratorium Teknik Sipil Universitas Sangga Buana (USB) YPKP.

\section{Penggunaan Alat}

Dalam melakukan penelitian, peneliti menggunakan alat-alat sebagai berikut :

1. Pompa air

2. Check Damn

3. Meteran

4. Curren Meter

5. Digital Camera

6. Benang Wol Putih

7. Alat bantu (ember, alat tulis, saringan pasir)

\section{Bahan Yang Digunakan}

Selain alat-alat, peneliti juga bahan-bahan yang mendukung pelaksanaan penelitian.

Bahan yang digunakan antara lain:

1. Pasir kerikil bersih bebas dari kandungan lumpur

2. Air PDAM 


\section{Proses Pengambilan Data}

Pelaksanaan penelitian ini dilakukan di laboratorium uji model hidrolik terbuka (laboratorium hidrolik) pada penampang dengan dimensi tinggi saluran $30 \mathrm{~cm}$ dan lebar $30 \mathrm{~cm}$ serta panjang ke seluruhan penampang saluran $350 \mathrm{~cm}$.

\section{Pengamatan dan Pengumpulan Data}

Hal yang dilakukan dalam penelitian ini adalah mengamati pola aliran air, yaitu perubahan debit dan perubahan kecepatan pada tiap percobaan, kemudian melakukan pengukuran - pengukuran guna memenuhi data yang dibutuhkan. Setelah itu data dikumpulkan dan diklasifikasikan sehingga bisa di analisa.

\section{Pengamatan Aliran}

Dalam Melakukan Penelitian Ini Yang Dilakukan Adalah Perilaku Gerak Air Atau Pola Aliran Air, Yaitu Aliran Turbulen Dan Aliran Kritis Yang Diakibatkan Dari Perubahan Debit Kecepatan Air, Sedimentasi Atau Gerusan Lokal Pada Dasar Saluran Yang Mengakibatkan Terjadinya Degradasi Dasar Aliran Sungai Dan Limpasan Permukaan Air Bendung Yang Menyebabkan Kerusakan Pada Mercu.

\section{Pengumpulan Data}

Jumlah data yang diambil pada penelitian ini adalah sebanyak 20 data hasil pengukuran yang terdiri dari 10 data hasil pengukuran dan menggunakan 2 buah pompa air dan 10 data hasil pengukuran dengan menggunakan 4 buah pompa, pengukuran yang diambil di lakukan pada saat air mengalir pada saluran air yang sebelumnya terdapat benda padat pada dasar saluran irigasi.

Adapun data - data yang diambil pada saat penelitian di laboratorium uji model hidrolik yaitu :

1. Debit air yang mengalir ;

2. Kecepatan aliran air.

3. Kedalaman air

4. Panjang saluran

5. Lebar saluran

\section{Perhitungan Data}

Perhitungan data dilakukan di laboratorium antara lain :

1. Pola Aliran

2. Penampang Saluran

3. Debit aliran

4. Gambar

\section{Analisis Data}

Pada bagian analisa data diuraikan proses penelitian secara sistematis, catatan lapangan dan bahan-bahan lain agar peneliti dapat menyajikan temuanya untuk mengetahui hasil dari pengujian atau penelitian yang telah dilakukan di laboratorium uji model hidrolik terbuka. Sehingga pada akhirnya didapatkan suatu kesimpulan 
dari hasil penelitian tersebut dan penelitian yang telah dilakukan dapat dipertanggungjawabkan.

\section{ANALISIS DATA DAN PEMBAHASAN}

\section{Analisis Data dan Hasil Penelitian}

Pada bab ini membahas mengenai hasil dari pelaksanaan penelitian yang dilakukan di laboratorium hidrolika Fakultas teknik unversitas sangga buana YPKP. Aliran air biasanya berbatasan dengan saluran dasar dan tebing di sebelah kiri atau kanan sungai. Secara umum sungai memiliki karakteristik sifat yaitu perubahan pada bentuk tampang aliran sungai. Air yang mengalir dalam sungai akan mengakibatkan proses penggerusan (scouring) pada bagian tanah dasarnya maupun daerah sekitar sungai, sebagai contohnya terjadi kerusakan tanggul sungai. Kerusakan tanggul sungai ini merupakan kerusakan yang diakibatkan oleh faktor kinerja debit sungai. Maka dari itu perlu di analisa sejauh mana kinerja debit sungai yang menyebabkan kerusakan tanggul sungai.

Tata cara melakukan pengambilan data, pelaksanaan, pengamatan dan pengamatan data eksperimen telah di jelaskan dalam metodologi penelitian. Adapun data hasil pengamatan pengamatan yang telah dilakukan di laboratorium uji model hidraulik adalah:

1. Besaran debit aliran (Q)

2. Tinggi permukaan air saat air mengalir (Y)

3. Tebal pasir (tp)

4. Debit Thompson $(\mathrm{Ht})$

5. Jarak cross section (1)

6. Gerusan (ds)

Dengan adanya lapisan pasir yang telah di padatkan di sepanjang saluran, maka data pengamatan dari penelitian ini adalah

a. Pengamatan perubahan arus aliran disekitar daerah sekitar saluran

b. Debit air yang mengair tiap satuan waktu

c. Pengamatan tinggi rendahnya permukaan saat air mengalir

d. Pengamatan kedalaman aliran disekitar bangunan pelimpah.

e. Pola gerusan

f. Kedalaman Gerusan hasil pengukuran (penelitian laboratorium)

g. Hubungan kedalaman gerusan dan waktu Running

h. Persamaan Laboratorium (Hasil 
Pengukuran)

i. Perbandingan

Kedalaman

gerusan hasil pengukuran

dengan penelitian

j. Total kehilangan energi $(\Delta \mathrm{E})$

k. Energi potensial (Ep) ,energi kinetik (Ek)dan energi spesifik (Es)

1. Luas penampang basah (At)

m. Lebar Tanggul yang longsor (BtL)

n. Pembukaan pintu Romijn atau Crump-de Gruyter

o. Analisis debit thompson.

\section{Data-Data Hasil Penelitian}

Data-data dari hasil pengamatan dalam penelitian pada saluran terbuka, perubahan dasar alur aliran sungai disusun berdasarkan rumusan-rumusan sebagaimana yang akan dibahas. Adapaun datadata yang diambil pada saat penelitian di laboratorium uji model hidrolik yaitu:

1. Debit air yang mengalir

2. Kedalaman aliran air

3. Kedalaman gerusan pada permukaan aliran dan disekitar talud.

4. Pola gerusan

5. Data topografi

6. Dokumentasi penelitian

7. Data pelengkap

Analisa Perhitungan Data
Analisis Debit Aliran (Q)

Analisa debit air (Q) berdasarkan persamaan dalam kajian pustaka pada Bab 2.

$Q=V \cdot A\left(\mathrm{~cm}^{3} / \mathrm{det}\right)$

Dimana:

$\mathrm{Q}=$ Debit aliran air pada alat ukur Thompson $\left(m^{3} / \mathrm{det}\right)$

$\mathrm{V}=$ kecepatan aliran $(\mathrm{cm} / \mathrm{det})$

$\mathrm{A}=$ luas penampang $(\mathrm{cm})$

Untuk perhitungan debit aliran Q yang dipakai adalah berdasarkan tinggi airpada alat ukur Thompson, perhitungan tersebut berdasarkan rumus :

$Q=1,38 \cdot H t^{\frac{5}{2}}$

Dimana :

$\mathrm{Ht}=$ kedalaman air yang diukur pada alat ukur Thompson (m).

Debit per satuan lebar q dihitung berdasarkan debit Q yang terjadi persatuan lebar saluran, berdasarkan rumus:

$\mathrm{q}=\frac{Q}{b} m^{2} / \mathrm{det}$

dimana:

$\mathrm{Q}=$ debit aliran berdasarkan rumus

Thompson, $\left.m^{3}\right) /$ det. 
$\mathrm{H}=$ lebar saluran pada model saluran.

Untuk analisa lebih lanjut persamaan diatas dapat dikembangkan menjadi :

$q=\frac{Q}{b}=\frac{V A}{q}$

Dengan persaman ini dapat diperbandingkan lebar saluran hasil pengukuran dengan lebar saluran hasil perhitungan dari analisa debit aliran.

\section{Deskripsi Perhitungan Data Penelitian}

Pendeskripsian data penelitian di lakukan dengan pengambilan sampel di praktek Uji Model Hidrolik . Terdapat beberapa jenis sampel, yaitu:

1. Debit aliran (q) per satuan Energi Kinetik (Ek)

2. Debit aliran (q) per satuan Energi Potensial (Ep)

3. Debit aliran (q) per satuan Energi Spesifik (Es)

4. Kecepatan aliran (V) per satuan $(\Delta \mathrm{E})$

5. Kecepatan aliran (V) per kedalaman gerusan analisa (dsa)

6. Kecepatan aliran (V) per kedalaman gerusan lapangan (dsl)

7. Bilangan $(\Delta \mathrm{E})$ per satuan bilangan Froude (Fr)

8. Bilangan Froude (Fr) per satuan bilangan $(\mathrm{dsa} / \mathrm{Ld})$
9. Bilangan gerusan analisa (dsa) per satuan $\left(\mathrm{Y}_{1} / \mathrm{L}_{1}-\mathrm{L}_{2}\right)$

10. Debit (Qt) per bilangan Froude (Fr)

Untuk proses pengambilan sampel yang di atas dapat di lihat di bawah ini:

1. Hubungan persamaan debit persatuan lebar (q) dengan nilai Energi Kinetik (Ek)

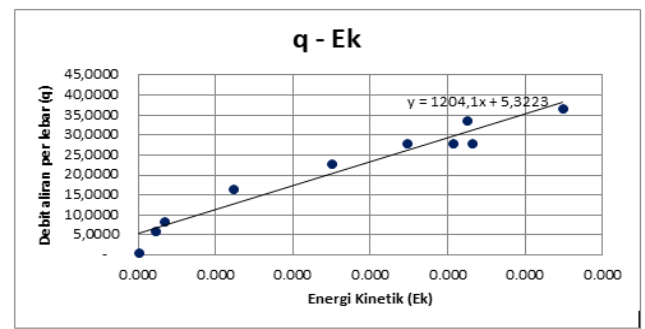

2. Hubungan persamaan debit per satuan lebar (q) dengan nilai Energi Potensial (Ep).

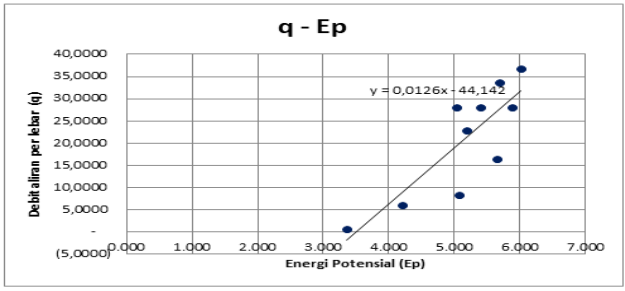

3. Hubungan persamaan debit persatuan lebar (q) dengan nilai Energi Spesifik (Es)

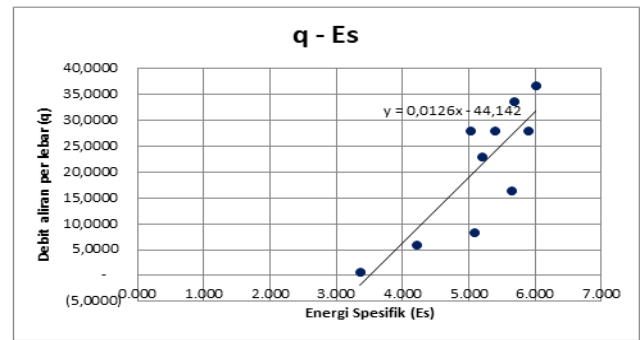


4. Hubungan persamaan kecepatan aliran (V) dengan Kehilangan Energi $(\Delta \mathrm{E})$.

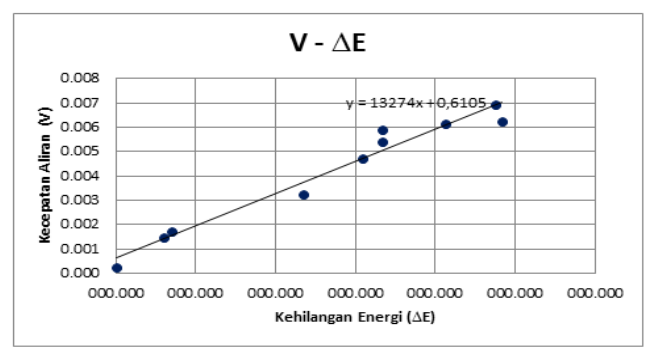

5. Hubungan persamaan kecepatan aliran (V) dengan nilai Gerusan Analisa (dsa).

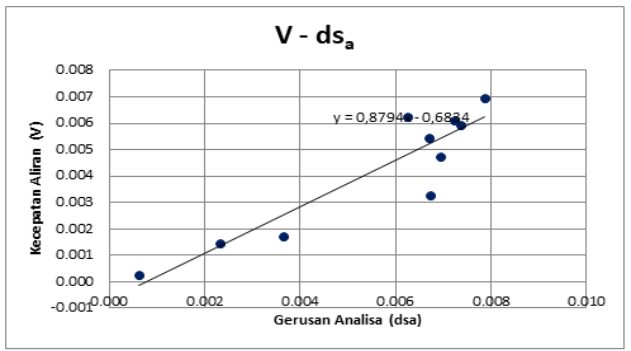

6. Hubungan Persamaan Kecepatan Aliran (V) dengan nilai Gerusan Lapangan (dsl).

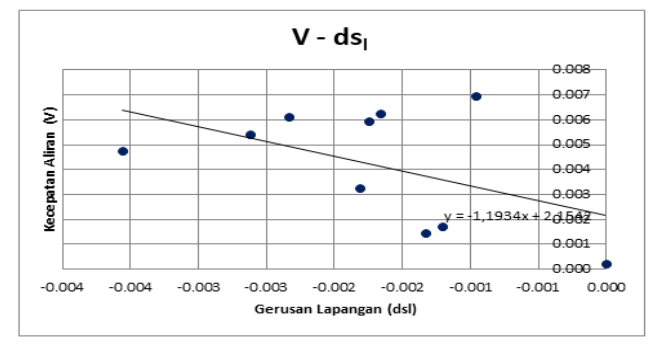

7. Hubungan Kehilangan Energi $(\Delta \mathrm{E})$ dengan Bilangan Froude (Fr).

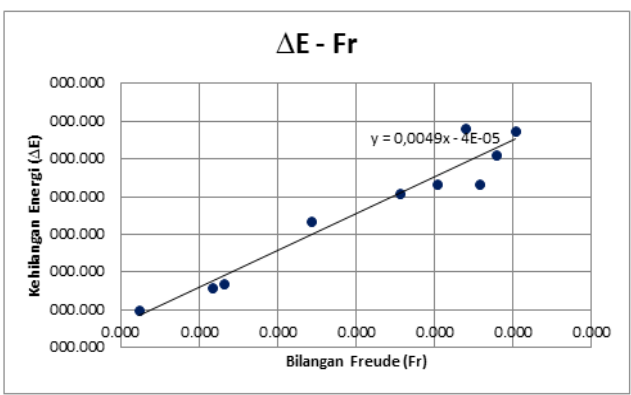

8. Hubungan Persamaan Bilangan Froude (Fr) dengan Nilai (dsa/Ld).

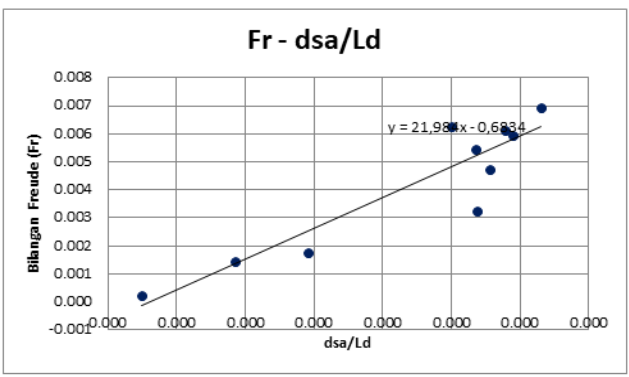

9. Hubungan Persamaan Gerusan Analisa (dsa) dengan Nilai ( $\mathrm{Y}_{1} / \mathrm{L}_{1}-$ $\left.\mathrm{L}_{2}\right)$.

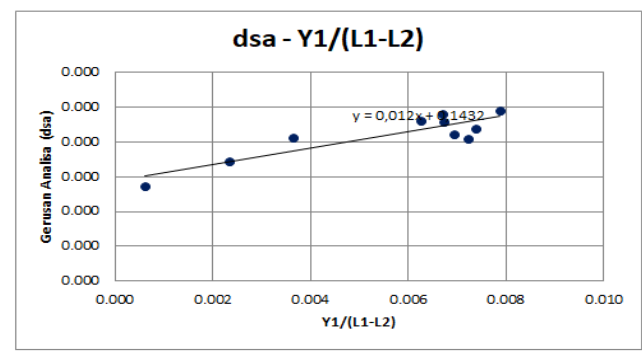

10. Hubungan Persamaan Debit (Q) dengan Bilangan Froude (Fr).

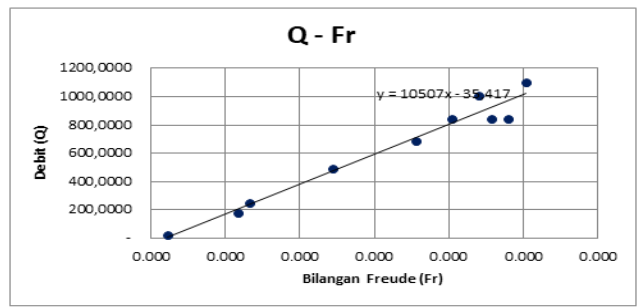

\section{KESIMPULAN DAN SARAN}

\section{Kesimpulan}

Berdasarkan hasil analisa dan pembahasan pada Analisis Pengendalian Air Permukaan di

Bawah Fly Over Dengan Sistim Drainase Terpadu Pada Kasus Ruas Jalan Mekar Mukti - Cibarusah Dengan Pendekatan Model Hidrolik Eksperimen 
Laboratorium, ditampilkan dalam bentuk tabel dan grafik, dapat ditarik kesimpulan:

1. Nilai Debit aliran persatuan lebar (q), akan sangat berpengaruh pada nilai Energi Kinetik (Ek), Energi Potensial (Ep) dan Energi Spesifik (Es).

2. Nilai Kecepatan aliran (V) sangat berpengaruh pada nilai Kehilangan Energi $(\Delta \mathrm{E})$, Kedalaman gerusan baik di lapangan (dsl) maupun pada saat tahapan analisa (dsa)

3. Semakin besar nilai bilangan Froude (Fr) maka akan semakin besar pula nilai kehilangan energi $(\Delta \mathrm{E})$ dan nilai kedalaman gerusan berbagi panjang (dsa/Ld).

4. Nilai bilangan Froude dipengaruhi juga oleh debit (Q).

\section{Saran}

Agar penelitian tentang debit yang mengakibatkan banjir yang bedampak pada kerusakan tanggul sungai di kemudian hari bisa dilakukan lebih baik, maka saran-saran yang penulis sampaikan bersifat membangun sebagai berikut:

1. Peralatan yang digunakan harus sesuai dengan peruntukannya, sehingga didapat data yang lebih detail dan akurat.
2. Peralatan ukur yang digunakan harus dikalibrasi secara rutin untuk mendapatkan hasil pengukuran/ penelitian yang lebih baik.

\section{DAF TAR PUSTAKA}

Affandi, D. (2009). Pengkajian Kapasitas Daya Dukung Tanah Gambut di Daerah Pengembangan Irigasi Di Kalimantan.

Brown, C.B. and W.T. Murphy, 1955, Konservasi dimulai dari DAS. Buku tahunan pertanian (Air).

Chow, Ven te, 1964, Buku panduan hidrologi terapan, Mc. Graw-Hill Buku perusahaan, New York.

Dr. Ir. Suyono Sosrodarsono dan Dr. Masateru Tominaga, Perbaikan dan Pengaturan Sungai, Jakarta, 2008.

Eagleson, PS, 1970, Hidrologi dinamis, Mc Graw- Hill, New York.

Ersin Seyhan, 1990. Dasar-Dasar Hidrologi, Gajah Mada University Press, Yogyakarta.

Gregory, K.J. and Walling, D.E., 1973, Bentuk cekungan drainase dan proses Pendekatan geomorfologi, Edward Arnold (Pub), Ltd. London.

Indra Dicky Saputra, Analisis Bentuk dan Jenis Tanggul Berdasarkan Pengaruh Aliran Turbulensi Terhadap Tekanan Aliran Normal dan Banjir Pada Studi Kasus Sungai Citarik, Bandung, 2011.

Joyce Martha dan Wanny Adidarma, --, Mengenal Dasar-Dasar Hidrologi, Penerbit Nova, Bandung.

Sosrodarsono Suyono dan Kensaku Takeda, 1977, Hidrologi untuk Pengairan. Pradnya Pramita, Jakarta.

Tossin Apandi, 2003, Staf Pengajar Jurusan Teknologi Pertanian, Fakultas Pertanian 